get treatment of the highest surgical and ethical standard: the interests of parents and patients may, we fear, be suffering as a result.

In the past two months both the Cleft Lip and Palate Association and the charity Changing Faces have received calls from anxious and confused parents and patients who have been told categorically that one course of surgery is preferable or, worse, that their surgery to date has been poor and needs revision. In our view, this is an unacceptable and unprofessional way for patients to be treated.

Our response to such distressing calls is to emphasise the importance of a multidisciplinary approach to the management of cleft lip and palate so that specialists, including psychologists, speech therapists, and paediatricians, together agree the priorities and objectives for surgery and therefore the most appropriate procedures in consultation with fully informed parents and patients. This is almost impossible at present because plastic surgeons and oral surgeons do not seem to be collaborating in clinical practice; rather, they seem to be in open competition.

As lay people we are unable to judge the strength of the arguments on both sides, and more research over 10-20 years may well be called for. Meanwhile, patients should not be pawns in a professional (unprofessional) feud. The Royal College of Surgeons or some other powerful agency urgently needs to organise discussion in camera before more distress is caused.

Cleft Lip and Palate Association,

GARETH DAVIES Chief executive

London SW1

JAMES PARTRIDGE Director

Changing Faces,

London W/2 1PN

1 Managing cleft lip and palate [letters]. $B M 7$ 1995;311:1431-3. (25 November.)

2 Markus T, Ward Booth P. Managing cleft lip and palate. BMf 1995;311:765-6. (23 September.)

\section{Risk of breast cancer is also increased among Danish female airline cabin attendants}

EDrTOR,-Eero Pukkala and colleagues report the incidence of cancer among a cohort of Finnish airline cabin attendants. ${ }^{1}$ Women made up the overwhelming majority of the cohort, and they were found to have an excess risk of cancer of the breast (number of cases observed, 20; standardised incidence ratio 1.87 (95\% confidence interval 1.15 to $2 \cdot 23)$ ). Excess risks were also found for cancer of the bone and leukaemia, on the basis of only two cases of each of these diseases.

In Denmark the incidence of cancer has been monitored for 17 years for the cohort of participants in the 1970 census. ${ }^{2}$ The standardised incidence ratio was calculated for each occupational group on the basis of the incidence for all economically active people. In 1970, 915 women were registered as airline cabin attendants in Denmark, while 362 men were registered as cabin attendants and 620 men as pilots. Table I shows the Danish data for the three types of cancer found in excess among

Table 1-Observed and expected numbers of cases of breast and bone cancer and leukaemia among Danis female and male airline crews

\begin{tabular}{|c|c|c|c|c|c|c|}
\hline & \multicolumn{2}{|c|}{ Breast } & \multicolumn{2}{|c|}{ Bone } & \multicolumn{2}{|c|}{ Leukaemia } \\
\hline & Observed & Expected & Observed & Expected & Observed & Expected \\
\hline $\begin{array}{l}\text { Women: } \\
\text { Cabin attendants }\end{array}$ & 14 & 8.67 & 0 & 0.04 & 0 & 0.56 \\
\hline $\begin{array}{l}\text { Men: } \\
\text { Cabin attendants } \\
\text { Pilots }\end{array}$ & $\begin{array}{l}0 \\
0\end{array}$ & $\begin{array}{l}0.02 \\
0.04\end{array}$ & $\begin{array}{l}0 \\
0\end{array}$ & $\begin{array}{l}0.04 \\
0.07\end{array}$ & $\begin{array}{l}1 \\
0\end{array}$ & $\begin{array}{l}0.38 \\
0.69\end{array}$ \\
\hline
\end{tabular}
649-52. (9 September.) albumin excretion rate differed between the two groups. Simply stating that these differences were not significant is inadequate: rates of change for each group, with confidence intervals, should be presented.

Little mention is made of retinopathy in this paper, but the EURODIAB insulin dependent diabetes mellitus complications study has shown that about half the patients with microalbuminuria have some degree of retinopathy, ${ }^{3}$ the progression of which is slowed by improved glycaemic control.

We believe that this study has important methodological limitations and that the target of improving glycaemic control in patients with insulin dependent diabetes mellitus with microalbuminuria should not be abandoned.

Lynge E, Thygesen L. Occupational cancer in Denmark. Cancer incidence in the 1970 census population. Scand $\mathcal{F}$ Work Environ Health 1990;16(suppl 2):1-35.

\section{Effect of intensive treatment in insulin dependent diabetes mellitus with microalbuminuria}

\section{Sample size was too small}

EDrToR,-The Microalbuminuria Collaborative Study Group concludes that intensive glycaemic control has no effect on the progression of albuminuria in people with insulin dependent diabetes mellitus who already have microalbuminuria. These conclusions have important implications for the care of diabetic patients and should not go unchallenged.

The main problem with this study, as the authors admit, is the sample size. If we assume that $21 \%$ of patients with microalbuminuria will progress to overt albuminuria, as shown in this and other studies, and we wish to show a reduction in progression by $50 \%$ in the intensively treated group (that is, a rate of progression of $10.5 \%$ ) with $80 \%$ power and a significance level of $5 \%$, we would need 412 participants (206 in each group) A more modest reduction in risk would require a larger sample. Thus the inclusion of just 70 patients is not enough, even if the risk of progression in the intensively treated group was close to zero.

The authors quote earlier studies showing significant reductions in risk associated with intensive treatment, which had similar sample sizes to theirs. But these results could partly have been due to a type I error. The authors also quote findings from the diabetes control and complications trial in support of their conclusions. In this trial the difference in the rate of change in albumin excretion rate in the group given intensive treatment compared with the group given conventional treatment was similar in patients with normal albumin excretion to that in patients with microalbuminuria at baseline. ${ }^{2}$ But this difference was significant only in those with normal albumin excretion rates as the number of participants with microalbuminuria was too small to provide adequate power.

The authors' study had two main outcome measures-progression to clinical albuminuria and rate of change in the albumin excretion rate. Only detailed results for the former are presented, and we are not shown how the rate of change in the

Department of Epidemiology and Public Health,

University College,

London WC1E 6BT

1 Microalbuminuria Collaborative Study Group, United Kingdom. Intensive therapy and progression to clinical albuminuria in patients with insulin dependent diabetes mellitus and microalbuminuria. BMף 1995;311:973-7. (14 October.)

2 Diabetes Control and Complications (DCCT) Research Group. Effect of intensive therapy on the development and progression of diabetic nephropathy in the diabetes control and compliof diabetic nephropathy in the diabetes
cations trial. Kidney Int 1995;47:1703-20.

3 Stephenson JM, Fuller JH, Viberti GC, Sjolie AK, Navalesi R, EURODIAB IDDM Complications Study Group. Blood pressure, retinopathy and urinary albumin excretion in pressure, retinopathy and urinary albumin excretion in IDDM: the EURODIAB IDDM complications study. Diabetologia 1995;38:599-603.

4 Diabetes Control and Complications Trial Research Group. The effect of intensive treatment of diabetes on the developmen and progression of long-term complications in insulin-dependent diabetes mellitus. N Engl F Med 1993;329:977-86.

\section{Work in non-insulin diabetes corroborates} study's findings

EDITOR,-The Microalbuminuria Collaborative Study Group suggests that arterial blood pressure rather than glycated haemoglobin concentration is the main predictor of progression from microalbuminuria to clinical albuminuria. ${ }^{1}$ Our work in non-insulin dependent diabetes corroborates these findings.

We undertook a prospective five year study of 42 patients (median (range) age 62 (32-71)) with noninsulin dependent diabetes and microalbuminuria (albumin excretion rate $>20 \mu \mathrm{g} / \mathrm{min}$ ). They were divided into two groups on the basis of diastolic pressure. Those with a diastolic pressure $>85 \mathrm{~mm}$ $\mathrm{Hg}$ on two occasions (group 1) were treated with an angiotensin converting enzyme inhibitor and the rest (group 2) were not. There was no significant difference in initial albumin excretion rate or haemoglobin $A_{1 c}$ concentration between the two groups. In group 1,17 of the 29 patients were taking antihypertensive treatment before the addition of the angiotensin converting enzyme inhibitor and 11 had complications (all macro-

Table 1-Blood pressure and albumin excretion rate (AER) at start and end of five year study in patients with non-insulin dependent diabetes and microalbuminura treated with angiotensin converting enzyme inhibitor (group 1) and serving as controls (group 2). Figures are medians (ranges)

Start of study End of study P value

Group 1

Blood pressure $(\mathrm{mm} \mathrm{Hg})$ :

Blood pressure (mm Hg): $170(120-252) \quad 146(120-200)<0.01$

$\begin{array}{cccc}\text { Diastolic } & 100(80-105) & 80(70-100) & <0.00 \\ \text { AER }(\mu \mathrm{g} / \mathrm{min}) & 48(20-282) & 30(7-200) & \text { NS }\end{array}$

Group 2

Blood pressure $(\mathrm{mm} \mathrm{Hg})$

Systolic $\quad 162(150-180) \quad 158(120-175) \quad$ NS

Siastolic $\quad 82(70-84) \quad 78(65-84)$ NS

AER $(\mu \mathrm{g} / \mathrm{min}) \quad 53(20-115) \quad 85(7-227) \quad<0.03$ 